\title{
Environmental Characteristics of Convective Systems During TRMM-LBA
}

\author{
Jeffrey B. Halverson and Thomas Rickenbach \\ Joint Center for Earth Systems Technology \\ University of Maryland Baltimore County \\ NASA GSFC Mesoscale Processes Branch \\ Greenbelt, MD 20771 \\ Biswadev Roy and Harold Pierce \\ Science Systems and Applications Inc. \\ NASA GSFC Mesoscale Processes Branch \\ Greenbelt, MD 20771 \\ Earle Williams \\ Parsons Laboratory \\ Massachusetts Institute of Technology \\ Cambridge, MA 02139
}

1 April, 2001

Submitted to Monthly Weather Review 


\section{ABSTRACT}

In this paper, data collected from 51 days of continual upper atmospheric soundings and TOGA radar at ABRACOS Hill during the TRMM-LBA experiment are used to describe the mean thermodynamic and kinematic airmass properties of wet season convection over Rondonia, Brazil. Distinct multi-day easterly and westerly lower tropospheric wind regimes occurred during the campaing with contrasting airmass characteristics. Westerly wind periods featured modest CAPE (1000 J kg-1), moist conditions (>90\% RH) extending through $700 \mathrm{mb}$ and shallow $(900 \mathrm{mb})$ speed shear on the order of $10^{-4} \mathrm{~s}^{-1}$. This combination of characteristics promoted convective systems that featured a relatively large fraction of stratiform rainfall and weak convection nearly devoid of lightning. The environment is very similar to the general airmass conditions experienced during the Darwin, Australia monsoon convective regime. In contrast, easterly regime convective systems were more strongly electrified and featured larger convective rain rates and reduced stratiform rainfall fraction. These systems formed in an environment with significantly larger CAPE (1500 J $\left.\mathrm{kg}^{-1}\right)$, drier lower and middle level humidities $(<80 \% \mathrm{RH})$ and a wind shear layer that was both stronger $\left(10^{-3} \mathrm{~s}^{-1}\right)$ and deeper $(700 \mathrm{mb})$. The larger CAPE resulted from strong insolation under relatively cloud-free skies (owing to reduced column humidity) and was also weakly capped in the lowest $1-2 \mathrm{~km}$, thus contributing to a more explosive growth of convection.

The time series of low- and mid-level averaged humidity exhibited marked variability between westerly and easterly regimes and was characterized by low frequency (i.e. multi-day to weekly) oscillations. The synoptic scale origins of these moisture fluctuations are examined, which include the effects of variable low-level airmass trajectories and upper- level, westward migrating cyclonic vortices. The results reported herein provide an environmental context for ongoing dual Doppler analyses and numerical modeling case studies of individual TRMM-LBA convective systems. 


\section{INTRODUCTION}

The Tropical Rainfall Measurement Mission (TRMM) component of the Brazilian Large Scale Biosphere-Atmosphere (LBA) experiment (hereafter referred to as TRMM-LBA) was conducted during January-February, 1999 to measure the dynamical, microphysical and environmental properties of mesoscale convective systems (MCS) during the wet season in Rondonia, Brazil. Numerous squall-type MCSs were sampled during this period, which was punctuated by contrasting westerly and easterly rainfall regimes (Silva Dias et al., 2001). These regimes are defined in terms of the direction of low-level wind prevailing for periods of several days to a week or more. The synoptic origins for these wind regime shifts are discussed in Rickenbach et al. (2001) and Petersen et al. (2001). Rickenbach et al. (2001) also found that the rainfall characteristics of these two regimes differ markedly in terms of their convective vs. stratiform raining fractions. In that study, eastward-propagating MCS were more monsoon-like in character featuring relatively weak convection and a larger fraction of rainfall incident from extensive stratiform cloud. Westwardpropagating squall lines, in constrast, derived more of their total rainfall from deeper and more intense leading-edge convection. The electrical properties of westerly vs. easterly MCS were also shown to strongly contrast, whereby easterly systems were significantly more electrified than their westerly counterparts (Williams et al., 2001). Similar monsoon and break regimes have been identified in other regions of the tropics, such as the Darwin, Australia region (Rutledge et al., 1992; Williams et al., 1992).

While Betts et al. (2001) discuss the TRMM-LBA boundary layer thermodynamics and fluxes in terms of regimes, the primary objective of this paper is to describe the deep column thermodynamic and kinematic properties and their association with the convective morphology. Environmental parameters examined here include measures of stability such as convective available potential energy (CAPE) and convective inhibition (CIN), the structure 
of vertical shear profiles and the vertical distribution of column water vapor. The thermodynamics and shear demonstrate inter-regime variations which play an important role in modulating the general properties of TRMM-LBA MCSs. The synoptic-scale origins of the various wind regimes are described in Rickenbach et al. (2001), in which easterly flow periods are attributed to the dominant subtropical Atlantic ridge, and westerly flow arises from stationary frontal systems extending into the deep tropics along the South Atlantic Convergence Zone (SACZ). An additional important objective of this paper address the large-scale origins of the moisture variability attending these circulation changes. Evidence will be presented that variations in column moisture content result from differences in both surface airmass trajectories, as well as the westward migration of upper tropospheric vortices. To a large extent, the moisture varilability in turn controls the thermodynamic stability in terms of CAPE and CIN. The overarching goal of the paper is to provide a descriptive physical context for ongoing, detailed observational and modeling studies of individual MCSs during TRMM-LBA.

This paper is organized as follows. Section 2 describes the various measurement systems and limitations of the data. Section 3 presents a synopsis of mean squall system properties as a function of five identified low-level wind regimes. In Section 4, key airmass properties are related to daily rainfall values and are presented in the form of regime-averaged quantities and vertical profiles. The origins of these properties and their hypothesized influence on squall system behavior is also discussed. Section 5 details specific synoptic-scale controls on airmass moisture variations. A summary of these results and concluding remarks is given in Section 6.

\section{DATA AND METHODS}

a. Upper Air Soundings 
The primary data for these studies were obtained from a mesoscale network of four radiosondes located in the vicinity of Ji Parana, Rondonia. The soundings sampled basic state variables at three-hourly intervals continuously for a 51 day period, from January 9 through February 28. This period included two westerly, two easterly and one zonally "neutral" wind regime. The array, shown in Figure 1, consisted of two types of sounding systems: Vaisala RS-80 radiosondes launched from Rolim de Moura and Rebio Jaru sites, and VIZ Mark II radiosondes released from ABRACOS Hill and Rancho Grande sites. Both vendors' instruments provided a 1-mb (or smaller) vertical sampling interval for pressure, temperature, relative humidity $(\mathrm{RH})$, windspeed and direction. Global Position System (GPS) windfinding techniques were utilized in both systems. Published accuracies of the VIZ and Vaisala radiosondes are as follows: Temperature $+/-0.2{ }^{\circ} \mathrm{C}$; pressure $+/-0.5 \mathrm{mb}$; relative humidity $+/-2 \%$; and winds $+/-0.5 \mathrm{~m} \mathrm{~s}^{-1}$. Coordinated radiosonde releases were nominally made every three hours at the sites; however, logistical issues periodically reduced the launch frequency to six-hourly, and also led to a multi-day shutdown of one of the sites (Rancho Grande) in the middle of the campaign.

For the purposes of this study we present upper air sounding data only for the ABRACOS Hill site. Observations collected there represent the longest and most complete record of the four sites. As of publication, quality control issues concerning the ABRACOS radiosondes remain, with analysis efforts ongoing in both the United States and Brazil. The data quality issues pertain to random errors in individual sounding temperature and humidity, as well as a systematic biases with respect to relative humidity (Zipser and Johnson, 1998). In this study, the sondes were examined only in terms of mean vertical profiles averaged over many days, and also in the format of a smoothed time series analyses. This should remove much of the effect of the random errors, while preserving relative changes in mean profiles representative of the various regimes. Our contention is that meaningful signals can be extracted which appear reasonable in the context of regime-averaged MCS properties and the 
larger scale forcing. It is important to note that when the the time-series averaged humidity at ABRACOS is compared with similar analyses at the other three sounding sites, the results yield equivalent trends aside from known systematic offsets in RH due to manufacturer bias.

\section{b. TOGA Radar and Electric Field Mill Facility}

Summary rainfall statistics for each regime were generated from ten-min, $1 \mathrm{~km} \times 1 \mathrm{~km}$ cartesian maps of radar reflectivity generated by the Tropical Oceans Global Atmosphere (TOGA) C-band $(5 \mathrm{~cm}$ ) radar located nearby ABRACOS Hill at Ouro Preto, Brazil. The NASA TOGA radar facility operated at a $5 \mathrm{~cm}$ wavelength with full volume scans were made every 10 min out to a range of $150 \mathrm{~km}$. Reflectivity data were corrected for calibration errors (Anagnatsou et al., 2001), converted to rainfall rate (Tokay et al., 2001), and partitioned into convective and stratiform raining regions (Steiner et al., 1995; Rickenbach and Rutledge, 1998). The computed summary statistics in Section 3 include mean convective and stratiform rain rates $\left(\mathrm{mm} \mathrm{hr}^{-1}\right)$ and percentage of stratiform rainfall. Regime-averaged statistics were computed for all precipitating features within the radar field of view, including the effects of both small, transient convective cells and the larger organized MCSs. In addition to multi-day regime averages, daily rain rate statistics (total, convective and stratiform conditional rain rates) were generated. Trends in the evolution of these rain metrics are correlated with changes in the upper tropospheric thermodynamics in Section 4.

Information on lightning activity was provided by field change antennae equipped with flat plate electrodes at ABRACOS Hill. The nominal detection range is on the order of $30-40 \mathrm{~km}$ radius within the larger envelope of TOGA radar coverage and included detections of both cloud-to-ground and intra-cloud discharges (Rust and MacGorman, 1987; Williams et al., 1992). The measure of MCS electrical activity used in this paper is the peak flash rate (PFR) which has been correlated with TRMM-LBA convective vigor (Williams et al., 2001). 


\section{CHARACTERISTCS OF TRMM-LBA CONVECTIVE SYSTEMS}

A general description of the precipitation, electrical and morphological properties of rain-producing systems in each regime between January 11February 28 is now presented. More specific details on rainfall and lightning characteristics are found in Rickenbach et al. (2001) and Williams et al. (2001). A total of twenty five MCSs were identified during TRMM-LBA, with the predominant form of organization being linear i.e. all MCSs examined featured a discrete leading-edge convective line with a variable degree of stratiform organization trailing the convection. Convective systems were identified through subjective examination of the lowest tilt $(0.5 \mathrm{deg})$ reflectivity maps generated by the TOGA radar at ten minute intervals, with range extending to $150 \mathrm{~km}$. Regions with locally high reflectivity and/or large reflectivity gradient were used to distinguish between convective and stratiform precipitation. The criteria used in this study to identify a linear MCS include: 1) convective organization, broken or continuous, that extends along a line for at least $100 \mathrm{~km}$; and 2) systems that maintain a coherent linear architecture for at least three hours.

Table 1 relates the bulk characteristics of TRMM-LBA rain systems to wind regime. The horizontal structure and evolution of a typical MCS sampled from each regime are also shown in Figure 2. Here, regimes have been defined according to the predominant direction of the lower $(<3 \mathrm{~km})$ tropospheric uwind component based on a height-time section analysis of the ABRACOS wind data (Figure 4), consistent with the synoptic-scale evolution of flow fields described in Rickenbach et al. (2001). Of the five regimes presented in the table (two westerly, two easterly and one neutral), only one convective line occurred during the first westerly regime (WLY1, January 11-19) while as many as nine lines were noted during the second easterly regime (ELY2, February 9-22). Also shown in Table 1 are the orientations of the linear portions of MCSs and their frequency of occurrence within each regime. In most cases, convective lines 
tended to orient perpendicular (within $30 \mathrm{deg}$ ) to the prevailing lower tropospheric zonal wind (Barnes and Sieckman, 1984; Weisman and Klemp, 1986; Keenan and Carbone, 1992; Garstang et al., 1994; LeMone et al., 1998) . During the neutral regime (NEUT, January 27-February 8), the regime-averaged zonal component was weak and variable below $3 \mathrm{~km}$, and MCS motion was determined primarily by a persistent low-level northerly flow.

The maximum peak flash rate (PFR) obtained for each regime varied considerably, ranging from a low of three flashes per minute (fpm) in the second westerly regime (WLY2, February 23-28) to a maximum of thirty fpm during the first easterly regime (ELY1, January 20-26). No values were reported during the neutral regime because of problems encountered in the operation of equipment. The PFR values suggest more lightning attended MCSs in both easterly regimes by a factor of two or more.

Mean convective rainfall rates during easterly regimes $\left(1.9 \mathrm{~mm} \mathrm{hr}^{-1}\right.$ for ELY1 and $1.4 \mathrm{~mm} \mathrm{hr}^{-1}$ for ELY2) were nearly twice that of the two westerly regimes $\left(0.8 \mathrm{~mm} \mathrm{hr}^{-1}\right)$ with the neutral regime ranking intermediate. Stratiform rain rate was remarkably invariant $\left(0.6 \mathrm{~mm} \mathrm{hr}^{-1}\right)$ across all five regimes sampled. However, the percentage of regime total rainfall associated with stratiform processes varied widely between regimes, with $44-46 \%$ of the rainfall generated by stratiform clouds ascribed to westerly MCSs, and only $24-30 \%$ originating in easterly regime systems.

The maximum horizontal extent of the stratiform rain shield varied widely during the experiment, ranging from $40 \mathrm{~km}$ to $220 \mathrm{~km}$. At least one MCS with a trailing stratiform region exceeding $150 \mathrm{~km}$ width occurred in every regime (Table 2), and in all regimes, stratiform rain was sometimes observed to develop along narrow ribbons or "streamers" projecting behind leading convection. These structures resulted from a differential motion between convective line propagation and upper level zonal flow (c.f. figures $2 b$ and $2 f$, and discussed further in Section 4 below). However, there were also seven instances of MCSs with relatively small stratiform shields (50 km wide or less) 
that clustered within and around the second easterly period (ELY2) from February 7 through February 23. In these cases, stratiform rain developed as a result of rapid in situ decay of a narrow convective line, rather than evolving into a long-lived and slowly expanding shield that trailed the leading edge. An example of these weak stratiform cases are shown in Figures $2 \mathrm{~d}$ and $2 \mathrm{e}$. Possible reasons for this class of weak stratiform morphology are discussed in Section 4.

While the general picture of easterly regime MCSs is one of more intense convective rainfall and heightened electrification, there are noteworthy differences in the convective intensity between ELY1 and ELY2. ELY1 systems were the most convectively vigorous of the entire experiment. For instance, PFR values exceeded $25 \mathrm{fpm}$ on three out of seven days within ELY1, while no PFR value exceeded 14 flashes per minute during the entire fourteen day period of ELY2. Furthermore, the mean convective rainrate for ELY1 systems exceeded that of ELY2 by $40 \%$, and the smallest stratiform rain fraction $(24 \%)$ of all five occurred during this period. The specific mechanisms responsible for the general differences between easterly and westerly convective systems, as well as possible reasons for the more energetic ELY1 convection, are explored in the next section.

\section{ENVIRONMENTAL PROPERTIES OF TRMM-LBA MCSs BY REGIME}

The relationship between daily integrated rainfall as measured by the TOGA radar and the ABRACOS thermodynamic environment is shown in Figure 3. Shown are time series analyses of (a) 24-hour conditional rain rates averaged over the radar scanning volume; (b) lower tropospheric $(1000-700 \mathrm{mb})$ layer mean relative humidity; (c) convective available potential energy (CAPE); and (d) convective inhibition (CIN). The sounding-derived quantities in panels $3 \mathrm{~b}-3 \mathrm{~d}$ are shown at three-hourly intervals from 9 January through 28 February and mapped to corresponding daily rain rates. In all panels, the trend through individual values (computed from running averages) is indicated by a heavy 
solid line. The specific method used to compute CAPE and CIN is now described.

Convective available potential energy (CAPE) and convective inhibition (CIN) values were computed for the ABRACOS Hill soundings by lifting a parcel with mean lower $500 \mathrm{~m}$ properties to the level of free convection and then to equillibrium level, following the standard pseudoadiabatic process. The averaged CAPE and CIN values were computed only for daytime and nightime conditions that were considered undisturbed. Categorization of soundings was made by subjectively examining each sounding's structure combined with radar analyses and field observations recorded at launch time. The undisturbed category contained those conditions which were 1) clearly pre-convective in nature; 2) were not released during precipitation of any intensity; and 3) were not launched in the immediate hours following passage of an intense MCS. The undisturbed sounding sample represents $67 \%$ of the total population of soundings $(n=281)$ used in the analysis. Also shown in Table 3 are regimeaveraged surface theta and theta-e obtained during the maximum point of their respective diurnal cycles. The surface values were obtained from the University of Virginia microflux tower which provided 1-min averaged measurements and was located adjacent to the ABRACOS Hill sounding release site (Betts et al., 2001).

This comparative time series analyses in Figure 3 highlight a relationship between variations in daily rainfall intensity and contrasting regime thermodynamics. The strongest coincidences between airmass properties and rainfall are most notable during the two easterly periods (ELY1 and ELY2). The largest daily averaged rain rates (exceeding $1.5 \mathrm{~mm} / \mathrm{hr}$ ) occured during these two periods (January 20-26 and February 7-23). There was a correpsonding increase in CAPE, with maximum values at or exceeding $1500 \mathrm{~J} \mathrm{~kg}^{-1}$ during the rainfall maxima, and also an increase in convective inhibition to values greater than $20 \mathrm{~J} \mathrm{~kg}^{-1}$. Relative mimima in CAPE $\left(\sim 1000 \mathrm{~J} \mathrm{~kg}^{-1}\right.$ or less) and CIN $(<20 \mathrm{~J} \mathrm{~kg}$ 1) correspond to periods of reduced daily rain rate, namely the westerly wind 
regimes at the beginning and end of the experiment and the zonally neutral regime between ELY1 and ELY2. During easterly flow conditions there was also an abrupt drying of the lower troposphere, manifest by a decrease in 1000-700 mb RH from $90 \%$ or greater to about $80 \%$. Figure 3 thus illustrates important changes in airmass properties which accompany shifts in the direction of prevailing winds, and the correlation of these changes with daily storm rainfall. More detailed information about these secular trends and their origins will be discussed in the next several sections.

Table 3 illustrates airmass thermodynamic and kinematic properties as regime averaged quantities. As documented in Section 3, easterly flow convection was more vigorous than its westerly counterpart, both in terms of electrical activity and amount of rain generated by the convective line. The metrics presented in Table 3 offer several possible mechanisms. First, the available thermodynamic energy in the form of CAPE is on the order of $50 \%$ larger for the easterly cases, and convective inhibition averages roughly twice that of the westerly regime. Reasons for the larger CAPE and CIN are apparent from examination of Figure 4, which shows mean thermodynamic soundings constructed for the easterly and westerly regimes based on the subset of undisturbed soundings. CAPE is uniformly larger throughout the entire parcel ascent path during easterly periods and the positive energy area extends through a deeper layer of troposphere. A uniform increase in CAPE is attributable to 2-3 $\mathrm{K}$ larger boundary layer temperatures and a steeper lapse rate below $750 \mathrm{mb}$. Lapse rates are identical above $750 \mathrm{mb}$ for both easterly and westerly regimes. The more energetic boundary layer results from reduced cloud cover in prevailing drier lower and middle tropospheric humidities.

Convective inhibition is also larger during the easterly regime. The larger CIN arises within the first $1.5 \mathrm{~km}$ of the atmosphere and serves to weakly "cap" growing thermals early in the afternoon and therefore increase their vigor once they erupt into the LFC (deep convective growth commonly commenced around 15 UTC or 11 am LST during TRMM LBA) (Carlson and Farrell, 1982; McGinley, 
1986). The mean easterly sounding shows no evidence of an elevated tradewindtype inversion, of the type that might be expected to arise from easterlies of Atlantic subtropical ridge origin. However, this type of inversion did infrequently occur; for instance, on January 26 several ELY1 prestorm soundings exhibited a pronounced warm, dry subsidence layer between $800-600 \mathrm{mb}$. We hypothesize that the combined effects of increased CAPE and CIN promote stronger updrafts leading to greater upward flux of moisture and thereby invigorated the mixed phase region (Zipser, 1994; Zipser and Lutz, 1994), increasing production of both rainfall and enhancing electrical breakdown. We also note that the mean environmental sounding for all neutral regime days is virtually identical to the mean westerly sounding shown in Fig. 4.

A second mechanism favoring stronger easterly convection likely was due to deeper and stronger lower tropospheric wind shear. The magnitude of the vertical shear was determined for the $0-3 \mathrm{~km}$ layer based on regime-averaged vertical profiles of $u$ - and $v$ - winds. During TRMM LBA this layer captured the most significant variation of wind structure in the lower and middle troposphere. It is well established that stronger shear promotes a greater degree of updraft tilt which, given a sufficient source of buoyancy, reduces water loading in cloud updrafts (Weisman and Klemp, 1986; Rotunno et al., 1988; Fovell and Ogura, 1989; Keenan and Carbone, 1992). Evidence for stronger updrafts in easterly flow convection is shown by Cifelli et al. (2001). An order of magnitude increase in the lower layer shear strength $\left(10^{-3} \mathrm{~s}^{-1} \mathrm{vs} .10^{-4} \mathrm{~s}^{-1}\right.$; Table 3) is noted for the easterly regime. Figure 5 shows a height-time section of zonal wind component for the entire TRMM-LBA experiment. The corresponding regime-averaged vertical profiles of $\mathrm{u}$ - and $\mathrm{v}$-wind components are shown in Figure 6. The $\mathrm{u}$-wind profiles for ELY1 and ELY2 are nearly identical and both exhibit a deep low-level speed maximum of about 5-6 $\mathrm{m} \mathrm{s}^{-1}$ at $3 \mathrm{~km}(700 \mathrm{mb})$. The v-wind profiles, while generally weaker, feature a northerly maximum near $3 \mathrm{~km}$. In contrast, sheared flow during westerly conditions was much shallower in both $u$ and $v$, with the wind maximum was located at the top of the boundary 
layer $(1 \mathrm{~km})$. The neutral wind profile exhibited a highly variable zonal direction below $3 \mathrm{~km}$ but retained modest shear with respect to its northerly component.

The wind profiles shown here are virtually identical to those found in a study of monsoon and break convective regimes over Darwin, Australia (Keenan and Carbone; 1989, 1992). Airmass characteristics of the Darwin monsoon versus break periods and attendant MCS properties are similar to the Rondonian westerly and easterly regimes, respectively. Figure 1 of Keenan and Carbone (1989, not shown) shows the mean vertical wind structures for these two regimes, with a moderate, $3-\mathrm{km}$ deep easterly shear $\left(10^{-3} \mathrm{~s}^{-1}\right)$ prevailing during break conditions. During the Darwin monsoon period, the westerly shear layer was much shallower $(1 \mathrm{~km})$ and weaker $\left(10^{-4} \mathrm{~s}^{-1}\right)$. It is also worthwhile to note that both CAPE and CIN were larger during the Darwin break versus monsoon, similar in both respects to the differences between Rondonian easterly and westerly thermodynamic environments.

A third reason for differences between regime MCS rainfall properties may be understood in terms of the highly variable moisture content of the column. Table 3 depicts layer-mean relative humidity values at ABRACOS Hill computed at three specific levels: Lower troposphere $(1000-700 \mathrm{mb})$ averaged, middle troposphere (700-300 mb) averaged and upper troposphere $(300-100 \mathrm{mb})$ average humidities. Below $300 \mathrm{mb}$ significantly drier ambient conditions prevailed during easterly flow. The reduction in available moisture during easterly periods, while still sufficient to support intense deep convection, may have promoted much smaller non-convective rain fractions (24-30\% for easterly vs. $44-46 \%$ for westerly rain characteristics) through increased sublimation and evaporation of hydrometeors generated within stratiform cloud. The precipitation efficiency of convective nimbostratus is known to be highly sensitive to column precipitable water (Ferrier et al., 1996). Cloud resolving model simulations using the Goddard Cumulus Ensemble (GCE) model (Tao et al. 1993) as well as observations from the TOGA Coupled Ocean Atmosphere Response Experiment (COARE) (Halverson et al., 1999) also suggest that 
decreases in middle tropospheric humidity are accompanied by reductions in both the areal coverage of stratiform rainfall and its contribution to the stormtotal rainfall amount. Further discussion on column water vapor variations and their origins will be presented in Section 5 .

Differences between the intensity of ELY1 and ELY2 regime convection were noted in Section 3. As Table 3 shows, the magnitude of both CAPE and vertical shear are very similar between these two regimes. However, the larger PFR values and $26 \%$ larger convective rain fraction of ELY1 systems may be attributed to a $40 \%$ larger CIN during this regime, which may have enhanced the boundary layer buoyancy. Greater solar heating was also associated with reduced cloudiness during ELY1. This was apparent in the diurnal maximum of surface potential temperature, whereby the ELY1 value of $306.0 \mathrm{~K}$ was $1.5 \mathrm{~K}$ larger than the surface theta observed during ELY2.

Finally, it was noted that several MCS occurring during the ELY2 period featured very small (or virtually nonexistent) stratiform rain regions. These cases include seven MCS events during the five-day period from February 7- 23. Two possible explanations are offered for this anomaly. First, the identified MCSs tended to cluster during the time of absolute minimum middle $(700-300 \mathrm{mb})$ and lower $(1000-700 \mathrm{mb})$ tropospheric relative humidity $\sim 55 \% \mathrm{RH}$ during the experiment (the times of these MCS are denoted by an " $X$ " in Figure 7, Section 5). The enhanced evaporation in this dry environment would severely constrain the horizontal growth of extensive stratiform cloud layers. The second reason is due to the orientation of the prevailing winds with respect to MCS motion. During the WLY1, WLY2 and ELY2. Figure 5 shows that the convective line motion opposed the direction of middle and upper tropospheric winds i.e. a reversing shear profile prevailed. Such a shear would enhance the horizontal expansion of stratiform cloud from its generating convective source. However, during the ELY2 regime, the line motion and upper level flow are directed in the same sense. Furthermore, Figure 5 shows that most of the identified weak-stratiform 
events (marked by an " $X "$ ) occur during a period of weakened middle and upper level flow.

\section{SYNOPTIC ORIGINS OF MOISTURE VARIATIONS BETWEEN REGIMES}

One of the strong determinants of stratiform rain fraction is due to the ambient column moisture content, particularly the humidity in the middle troposphere where precipitating nimbostratus originates. As shown in Table 3, there was significant inter-regime modulation of humidity. Figure 7 presents a time series analysis of relative humidity at ABRACOS Hill for the entire TRMMLBA campaign. Temporal changes are expressed as mean humidities averaged with respect to three layers: $1000-700 \mathrm{mb}$ (lower troposphere), 700-300 mb (middle troposphere) and 300-100 mb (upper troposphere). The thin tracing in Figure 7 shows the instantaneous (i.e. three-hourly) humidity values from individual soundings, whereas the heavy dashed line indicates a 30-point running average (essentially a four-day filter). This smoothed analysis reveals pronounced, low-frequency trends in the humidity behavior. It should be noted that this same analysis carried out at the other three network sounding sites (not shown) revealed similar patterns of humidity variation.

In general, atmospheric conditions were substantially drier during the two easterly wind regimes, averaging about $80 \%$ relative humidity in the lowermost layer and between $55-60 \%$ in mid-levels. This contrasts with a much moister lower troposphere with $\mathrm{RH}>90 \%$ during WLY1 and WLY2 and a moister middle level troposphere (70-80\% RH). The mean $\mathrm{RH}$ exceeding $90 \%$ probably reflects the frequent occurrence of stratiform rain conditions (particularly at night), and possibly also a moist bias characteristic of the VIZ radiosonde moisture sensor (Zipser and Johnson, 1998). The neutral period between ELY1 and ELY2 was also considerably moister throughout the column and contrasts with the twin dry periods. The degree of humidity variation in the upper 
troposphere $(100-300 \mathrm{mb})$ remained very small throughout the experiment and is therefore not discussed in detail.

During the two easterly regimes, a "dry" (in the relative sense) lower troposphere appeared to coincide with dry conditions at mid- levels. However, this coincidence appeared to be transient, as the trends in humidity between these two layers were not phased during most other times. Consider that between February 5-8, the lowest layer was very moist (90\% RH) while the middle levels were very dry $(55 \% \mathrm{RH})$. Also, the driest low-level conditions during ELY1 occurred early in this period (January 20) while the driest middle level conditions did not occur until a week later (January 27). During this seven day period, the low levels underwent steady moistening while the middle levels expressed progressive drying. This behavior implies that different atmospheric processes may be operating simultaneously to change the moisture content of the various levels.

An examination of NASA Data Assimilation Office (DAO) averaged synoptic wind fields for easterly vs. westerly periods provides insight into one possible mechanism responsible for modulating the lower tropospheric humidity. Figure $8 \mathrm{a}$ and $8 \mathrm{~b}$ shows the $850 \mathrm{mb}$ winds averaged for westerly and easterly periods, respectively, during TRMM-LBA. During westerly flow, the subtropical anticyclone was positioned southeast of South America. This resulted in a broadly recurving flow across northern Brazil, with the airmass originating over the tropical Atlantic. The near-equatorial easterlies were deflected by the Andes and forced to cross the equator, entering Rondonia as a northwesterly current. The Atlantic source flow thus experienced a long, uninterrupted fetch over moist rain forest canopy. Fluxes of water vapor from the wet season forest (due to evapotranspiration) can lead to substantial moistening of the boundary layer and promote high mixing ratios (Martin et al., 1988). This long over-forest fetch would thus serve to maintain the high humidity content of the Atlantic source air against convective rainout, perhaps through a deep layer via the action of both dry and moist convective mixing. 
In contrast, the easterly regime flow (Figure $8 \mathrm{~b}$ ) occurred in a setting whereby the subtropical anticyclone shifted north and west, resulting in a much more direct current across all of Brazil. There was no recurvature of easterlies across northern Brazil, and the fetch of air across Rondonia was thus considerably shortened. Furthermore, the airmass crosses the semi-arid Brazilian Highlands east of Rondonia. A combination of sparse or non-existent rain forest canopy, semi-aridity (the Highlands to the east of Rondonia receive average annual rainfall of less than $2000 \mathrm{~mm}$, compared to greater than $4000 \mathrm{~mm}$ in the interior forest north of Rondonia [Sombroek, 1999]) and gradual downsloping of air along the western face of the Highlands (terrain relief $\sim 1000 \mathrm{~m}$ ) probably dried this airmass. The progressive increase in low layer moisture content after absolute dry periods (January 18 and February 11, Figure 7) may reflect modification of the airmass through the cumulative effects of regional-scale evapotranspiration.

We now direct our attention to the issue of middle level humidity variation. Some of the moisture changes in this layer may result from the action of low level airmass trajectories extending through a deeper layer. But there remains another possible mechanism. An examination of synoptic-scale patterns of humidity across much of Brazil was facilitated by Geostationary Observatory Environmental Satellite (GOES) imagery depicting the middle-tropospheric water vapor channel $(6.7 \mu \mathrm{m})$. Successive half-hourly images were animated to observe changes in moisture throughout the entire experiment. As Figure $7 \mathrm{~b}$ shows, there are two key periods of interest, namely the episodes of 700-300 mb drying that occur between January 18-27 and February 2-14. These episodes may be the result of westward propagation of synoptic-scale upper-level cyclones. These cyclones are regularly occurring features during the wet season and are associated with upper level convergence and suppression of convection on their western side (Kousky and Gan, 1981). The migration of these vortices was implicated as a reason for the transient reversal of upper-level meridional winds over Rondonia during the TRMM-LBA (Rickenbach et al., 2001). 
Figure 9a shows a sequence of moisture channel images for the period 2226 January. Frames at $00 \mathrm{Z}$ (left column) and $12 \mathrm{Z}$ (right column) on each day are both shown, so that the evolution of upper level features can be traced during the convectively active portion of the diurnal cycle (00Z) and the suppressed early morning period $(12 \mathrm{Z})$. Following the red arrow in this image we note a weak upper level cyclone and its associated tongue of dry air advecting from the east, with its western edge arriving at the TRMM LBA site (heavy white circle) by 26 January. From Figure $7 \mathrm{~b}$ note that the minimum mid-level RH also occurred on January 26. The green arrow in Figure $9 \mathrm{~b}$ points out a second, smaller and less well defined cyclone which also advects dry air into the TRMM-LBA region around 24-25 January. While appearing subtle in static images, animation of the frames clearly depicts the cyclonic rotation and translation of these upper level features.

The most pronounced drying in the $700-300 \mathrm{mb}$ layer occured during early February. Figure $9 \mathrm{~b}$ shows a more robust example of a westward propagating upper level cyclone during this period (red arrows). The swirl of dry air associated with this feature arrived at the TRMM-LBA site by $12 \mathrm{Z} \mathrm{Feb} 4$, in good agreement with the drying trend noted in Figure $7 \mathrm{~b}$ during 1-5 February. One item to note, though, is that the cyclones appeared to weaken and lose definition on each successive day. As the cyclones translate westward, it is likely that the dry air contained within their cores was gradually moistened by repeated afternoon convection.

The drying of the middle layers in response to these cyclones exerts a marked effect on the convective system morphology within easterly regimes. On the one hand, the reduction in middle and upper level cloudiness permited stronger solar heating, leading to greater instability and stronger updrafts. On the other hand, the drier mid-level environment promoted enhanced evaporation and sublimation of moisture in the MCSs that did develop, diminishing both the areal coverage of stratiform cloud and also the stratiform rainfall fraction. As the 
results in Section 3 show, both of these impacts were observed in the summary statistics (Table 1 and Table 3 ) that characterized the easterly regime systems.

\section{SUMMARY AND CONCLUSIONS}

In this paper, data collected from 51 days of continuous upper air soundings at ABRACOS Hill during TRMM-LBA were used to describe the general thermodynamic and kinematic airmass properties of wet season convection over Rondonia, Brazil. As presented in this study and in others, convective properties contrast significantly between periods dominated by lower tropospheric easterlies versus lower tropospheric westerlies. Westerly regime rain systems featured mean convective rain rates that were half the magnitude of those in easterly systems, and the fraction of stratiform rainfall generated was nearly twice as large for westerly disturbances. The mean daily maximum flash rate was 4-5 times greater in the easterly than in the westerly regime (Williams et al., 2001).

The time series of daily-averaged conditional rain rates was well correlated with changes in airmass CAPE, CIN and lower tropospheric humidity. Bulk thermodynamic properties from the ABRACOS soundings averaged according to regime show that the westerly periods had a mean CAPE of around $1000 \mathrm{~J} \mathrm{~kg}^{-1}$ and high humidity (> 90\%) in the lower half of the troposphere. Mostly cloudy to completely overcast conditions prevailed, interspersed by organized convective lines, reducing the insolation and leading to lower CAPE. Mean shear profiles indicated a shallow westerly speed maximum near $900 \mathrm{mb}$ but the shear was weak, on the order of $10^{-4} \mathrm{~s}^{-1}$. These conditions were remarkably similar to the monsoon convective regime described for the Darwin, Australia region in 1987-1988 (Keenan and Carbone, 1992). In both Australia and Brazil, the high moisture, moderate CAPE and low windshear conditions appeared to promote convective systems which produce large fractions of 
stratiform rainfall and weak convection nearly devoid of lightning (Cifelli et al., 2001; Williams et al., 1992).

In contrast, the convective environment during TRMM-LBA easterly regimes was one in which partly cloudy to sunny skies prevailed, punctuated by vigorous afternoon squall lines that were often strongly electrified. The mean airmass properties featured significantly larger CAPE (1500 J kg-1), drier lower and middle level humidities and a wind shear layer that was both stronger $\left(10^{-3}\right.$ $\left.\mathrm{s}^{-1}\right)$ and deeper $(700 \mathrm{mb})$. The lower unstable boundary layer air was also weakly capped in the 1-2 km layer, which may have enhanced the release of instability. More intense updrafts were observed in easterly regime convection (Cifelli et al., 2001) which were a direct consequence of greater instability and deeper, stronger shear. The reduced stratiform rainfall fraction may have resulted from enhanced evaporation and sublimation of precipitation in the drier prevailing airmass. Further reductions in the stratiform raining fraction during the second easterly regime also likely resulted from weakened upper tropospheric winds, which limited the horizontal spread of condensate from the convective portion of mesoscale lines. Both the convective system properties and convective environment for TRMM-LBA easterly regime storms also strongly parallel those of the Darwin, Australia continental break period (Cifelli and Rutledge, 1994).

The column humidity in the environment of convection varied markedly between westerly and easterly regimes in the manner of low frequency (i.e. multi-day to weekly) oscillations. We hypothesize that alternating periods of drying and moistening in the lower levels $(1000-700 \mathrm{mb})$ were the result of different surface trajectories undertaken by Atlantic Ocean source air. In the case of the westerly regimes, blocking of low level flow by the Andes forced the air to recurve across a broad fetch of Amazon rain forest. Evapotranspiration of moisture during this long trajectory's passage over dense forest canopy maintained the airmass moisture content against depletion from rainout and contributed to large relative humidities. During the easterly periods, the air 
trajectory shifted to straight-in easterly flow off the Atlantic. Before arriving in Rondonia, the oceanic air traversed a broad region of highlands devoid of rich forest cover and one which is substantially more arid than the continental interior. The drier nature of the surface combined with broad downsloping of the airmass as it settled westward may have promoted drying of the airmass low levels.

Trends in lower and middle level humidity content occasionally coincided, i.e. dry conditions prevailed through a deep layer $(300 \mathrm{mb})$ on several days during both easterly regimes. However, the trends were also frequently decoupled. One explanation for middle level dry episodes was that they arose from the action of westward-moving upper-level cyclonic vortices containing dry air. The timing of these dry air intrusions was such that they occasionally coincided with episodes of lower tropospheric easterlies, and the entire column thus experienced a marked reduction in water vapor. During February 11-14, for instance, total column humidity was at its absolute minimum (i.e. $30 \% \mathrm{RH}$ in mid-levels), and several of the squall lines that developed during this time produced very little stratiform rain.

This investigation provides a context for the general environmental forcing of cloud systems in ongoing dual-Doppler analyses (Cifelli et al., 2001) and numerical modeling case studies (Tao et al., 2001). Cloud resolving model (CRM) experiments can clarify the relative importance of environmental parameters discussed here such as shear strength vs. CAPE during the different TRMM-LBA convective regimes. In addition, significant mesoscale variations among moisture and winds were often present within the TRMM-LBA sounding network. An understanding of these gradients is just as important as the mean differences between regimes and may play an equal role in defining the wide variety of convective morphology observed during the Rondonian wet season.

\section{ACKNOWLEDGEMENTS}


The authors which to acknowledge the continuing support of Dr. Ramesh Kakar, NASA Headquarters Dynamics and Thermodynamics Research Branch. This work was funded by a grant in support of Tropical Rainfall Measurement Mission (TRMM) research. The authors also wish to thank J. Gerlach and the TOGA radar crew of the NASA Wallops Flight Facility for their hard work in the field, as well as the Brazilian contributors to that operation.

\section{REFERENCES}

Anagnatsou, E.N. and C.A. Morales, 2001: Rainfall estimation from TOGA radar observations during the LBA field campaign. J. Geophys. Rev., submitted.

Barnes, G.M. and K. Sieckman, 1984: The environment of fast- and slow-moving tropical mesoscale convective cloud lines. Mon. Wea. Rev., 112, 1782-1794.

Betts, A.K., J.D. Fuentes, M. Garstang and J.H. Ball, 2001: Surface diurnal cycle and boundary layer structure over Rondonia during the rainy season. J. Geophys. Res., submitted.

Carlson, T. and R. Farrell, 1982: The lid strength index as an aid in predicting severe local storms. Natl. Wea. Dig., 8, 27-39.

Cifelli, R. and S. Rutledge, 1994: Vertical motion structure in Maritime Continent Mesoscale Convective Systems: Results from a 50-MHz profiler. J. Atmos. Sci., 51, 2631-2652.

Cifelli, R., W.A. Petersen, L.D. Carey and S.A. Rutledge, 2001: Radar observations of the kinematic, microphysical and precipitation characteristics of two MCSs in TRMM-LBA. J. Geophys. Rev., submitted.

Ferrier, B.S.; J. Simpson and W.-K. Tao, 1996: Factors responsible for precipitation efficiencies in midlatitude and tropical squall simulations. Mon. Wea. Rev., 124, 2100-2125.

Garstang, M., H.L. Massie, Jr., J. B. Halverson, S. Greco and J. Scala, 1994: Amazon Coastal Squall Lines. Part I: Structure and kinematics. Mon. Wea. Rev., 122, 608-622. 
Greco, S., R. Swap, M. Garstang, S. Ulanski, M. Shipman, R.C. Harriss, R. Talbot, M.O. Andreae and P. Artaxo, 1990: Rainfall and surface kinematic conditions over central Amazonia during ABLE 2B. J. Geophys. Res., 93, 17,001-17,014.

Halverson, J.B., B.S. Ferrier, T.M. Rickenbach, J. Simpson and W.-K. Tao, 1999: An ensemble of convective systems on 11 February 1993 during TOGA COARE: Morphology, rainfall characteristics and anvil cloud interactions. Mon. Wea. Rev., 127, 1208-1228.

Keenan and Carbone, 1992: A preliminary morphology of precipitation systems in tropical northern Australia. Quart. J. Roy. Meteor. Soc., 118, 283-326.

Kousky, V.E. and M. A. Gan, 1981: Upper tropospheric cyclonic vortices in the tropical South Atlantic. Tellus, 33, 538-551.

LeMone, M..A., E. J. Zipser, and S. B. Trier, 1998: The role of environmental wind shear and thermodynamic conditions in determining the structure and evolution of mesoscale convective systems during TOGA COARE. J. Atmos. Sci., 55, 3493-3518.

Martin, C.L., D. Fitzjarrald, M. Garstang, A.P. Oliveira, S. Greco and E. Browell, 1988: Structure and growth of the mixing layer over the Amazonian rain forest. J. Geophys. Res., 93, 1361-1375.

McGinley, J., 1986: Nowcasting mesoscale phenomena, Chapter 28 in Mesoscale Meteorology and Forecasting, ed. P.S. Ray, Amer. Meteor. Soc.

Rickenbach, T.M., R.N. Ferreira, J. Halverson and M.AF. Silva Dias, 2001:

Mesoscale properties of convection in western Amazonia in the context of large-scale wind regimes. J. Geophys. Rev., submitted.

Rotunno, R., J.B. Klemp and M.L. Weisman., 1988: A theory for strong, longlived squall lines. J. Atmos. Sci., 45, 463-485.

Rust, W.D. and D.R. MacGorman, 1987: Techniques for measuring electrical parameters of thunderstorms, Chapter 8 in: Instruments and Techniques for Thunderstorm Observation and Analysis, Ed., E. Kessler, University of Oklahoma Press, Norman, 268 pp. 
Rutledge, S.A., E.R. Williams and T.D. Keenan., 1992: The Down Under Doppler And Electricity Experiment (DUNDEE): Overview and preliminary results. Bull. Amer. Meteor. Soc., 73, 3-16.

Silva Dias et al., 2001: Clouds and rain processes in a biosphere atmosphere interaction context in the Amazon region. J. Geophys. Rev., submitted.

Steiner, M., R.A. Houze and S.E. Yuter, 1995: Climatological characterization of three-dimensional storm structure from operational radar and rain gauge data. J. Appl. Meteorol., 34, 1978-2007.

Tao, W.-K., C.-H. Sui, B. Ferrier, S. Lang, J. Scala, M.-D. Chou, and K. Pickering., 1993: Heating, moisture and water budgets of tropical and midlatitude squall lines: Comparisons and sensitivity to longwave radiation. J. Atmos. Sci., 50, 673-690.

Tokay, A., W. Krajewski and A. P. Fihlo., 2001: Measurements of drop size distribution in the southwest Amazon region. J. Geophys. Rev., submitted.

Weisman, M.L. and J.B. Klemp, 1986: Characteristics of convective storms. Mesoscale Meteorology and Forecasting, P.S. Ray, Ed., Amer. Meteor. Soc., 331-358.

Williams, E.R., S.A. Rutledge, S.G. Geotis, N. Renno, E. Rasmussen and T. Rickenbach, 1992: A radar and electrical study of tropical "hot towers". J. Atmos. Sci., 49, 1386-1395.

Williams, E.R. et al., 2001: The Green Ocean over the Amazon: Implications for cloud electrification. J. Geophys. Rev., submitted.

Zipser, E.J.,1994: Deep cumulonimbus cloud systems in the tropics with and without lightning. Mon. Wea. Rev., 122, 1837-1851.

Zipser, E.J. and K. Lutz, 1994: The vertical profile of radar reflectivity of convective cells: A strong indicator of storm intensity and lightning probability. Mon. Wea. Rev., 122, 1751-1759.

Zipser, E.J. and R.H. Johnson, 1998: Systematic errors in radionsonde humidities: A global problem? 10 ${ }^{\text {th }}$ Symposium on Meteor. Obs. And 
Instrument., Phoenix, AZ, AMS.

\section{Figure Captions}

Figure 1. Location of TRMM LBA sounding network and TOGA radar (T) at ABRACOS Hill, Ji Parana, Rondonia, Brazil. The TOGA radar site is indicated by the " $\mathrm{T}$ ", the S-pol radar site by " $\mathrm{S}$ ", and numbers refer to raingage site locations. Triangles denote the mesoscale sounding network. Solid concentric circles surrounding the S-pol site refer to 150 and $300 \mathrm{~km}$ range rings; similar ranges for the TOGA radar are shown by dotted concentric circles. Solid circles overlapping along the baseline between the TOGA and S-pol radars specify the dual-Doppler lobes.

Figure 2. TOGA radar CAPPI rainfall maps showing orientation, movement, evolution and morphology of typical MCS during various wind regimes. White arrows indicate direction of MCS propagation; red arrows show temporal continuity between successive views in the MCS evolution. Radius of radar coverage extends $150 \mathrm{~km}$. Color scale ranges from low reflectivity values (blue) to high (red).

Figure 3. Relationship between (a) daily averaged conditional rain rate $(\mathrm{mm} \mathrm{hr}$ 1) integrated over the area of TOGA radar coverage and (b) - (d) thermodynamic quantities derived from the ABRACOS Hill soundings. (b) three-hourly layer-mean relative humidity values for all levels between 700$1000 \mathrm{mb}$; (c) individual three-hourly values of CAPE $\left(\mathrm{J} \mathrm{kg}^{-1}\right)$, derived from a 500-m averaged parcel for undisturbed soundings; and (d) individual values of CIN ( $\left.\mathrm{J} \mathrm{kg}^{-1}\right)$, again computed from a $500-\mathrm{m}$ averaged parcel for undisturbed soundings. Solid curves drawn through individual data points reflect a running average of all values.

Figure 4. Regime-averaged soundings at ABRACOS Hill for a) mean westerly conditions and b) mean easterly conditions. 
Figure 5. Height time analysis of sounding u-wind component at ABRACOS Hill. The X's denote time of occurrence of MCSs featuring small or absent stratiform regions. Warm colors (yellow and red) denote westerly flow; cold colors (blue and violet) indicate easterlies. Color fill intervals are every 2.5 $\mathrm{m} / \mathrm{s}$. Solid white line separates regions of easterly and westerly flow. Black arrows show general direction of MCS propagation during regimes (i.e. from the east, west or north).

Figure 6. Mean u- and v-wind profiles constructed from ABRACOS Hill sondes during five lower tropospheric wind regimes.

Figure 7. Time series of layer-averaged relative humidity from ABRACOS Hill radiosondes for a) lower troposphere $(1000-700 \mathrm{mb})$ and b) middle troposphere $(700-300 \mathrm{mb})$. X's denote time of occurrence of MCSs featuring small or absent stratiform regions.

Figure 8. Analyses of DAO $850 \mathrm{mb}$ winds averaged for TRMM LBA a) westerly regimes and $b$ ) easterly regimes.

Figure 9. Sequence of GOES water vapor channel $(6.7 \mu \mathrm{m})$ images during January 22-26 (a) and February 1-5 (b) showing the evolution of westwardpropagating upper level cyclones and associated dry air. While circle in each image denotes the location of the TRMM-LBA experimental network. Red and green arrows point to center of cyclonic vortices. 


\section{TRMM-LBA Sounding Network}

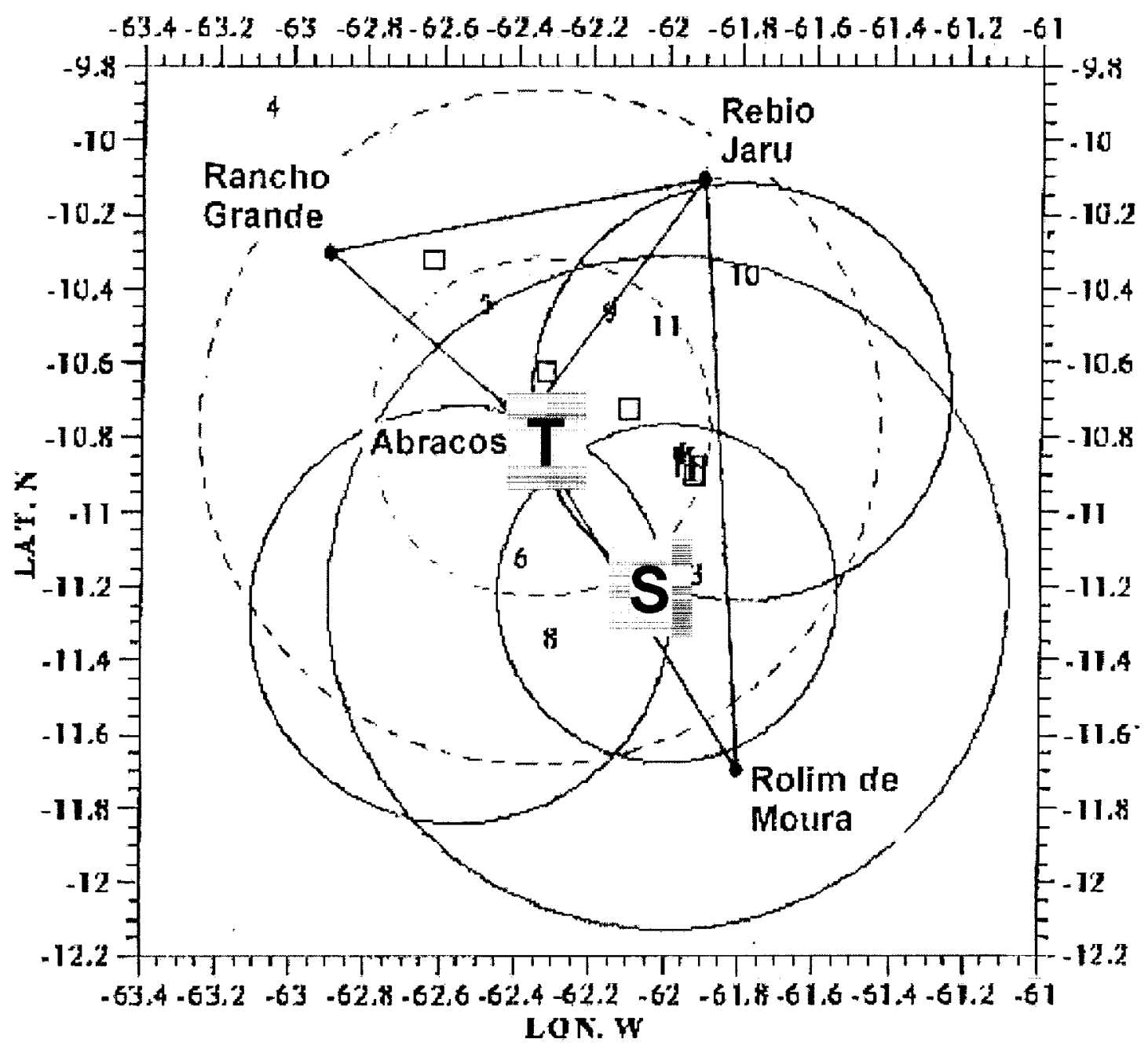


Figure 2

a)

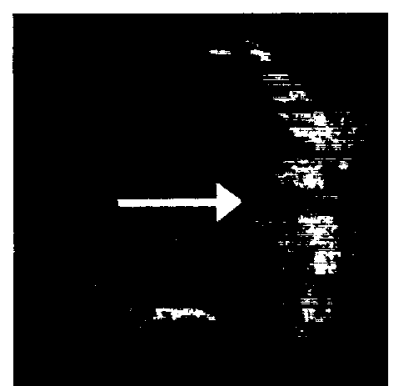

b)

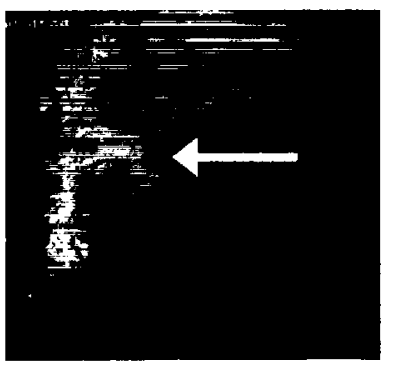

c)

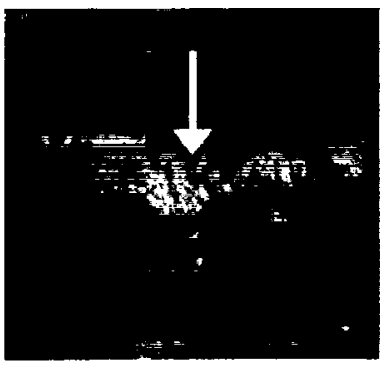

d)

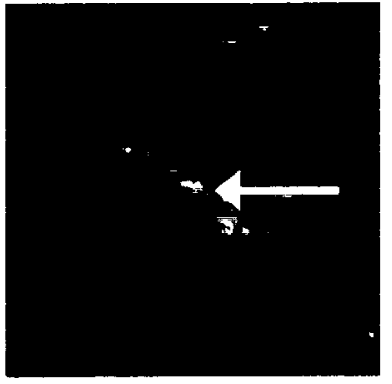

e)

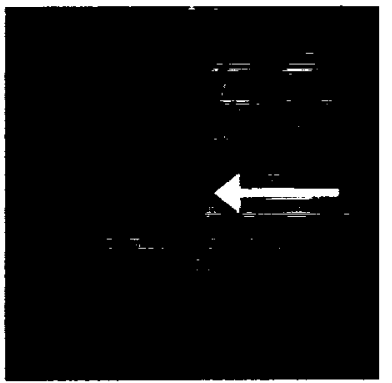

f)

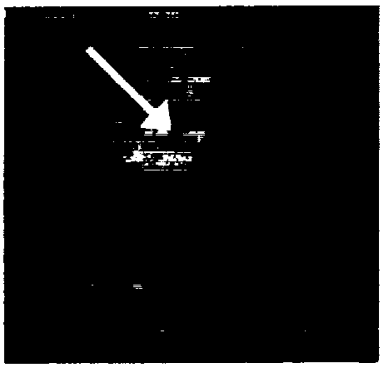

WLY1

Jan 14

$1910 \mathrm{Z}$

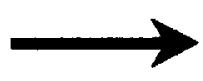

ELY1

Jan 25

1149 Z

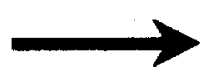

NEUT

Jan 31 1609 Z

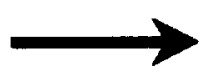

\section{ELY2}

Feb 11

1850 Z

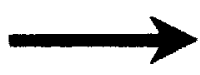

\section{ELY2}

Feb 18 0539 Z

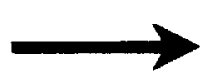

WLY2

Feb 24 $0630 \mathrm{Z}$

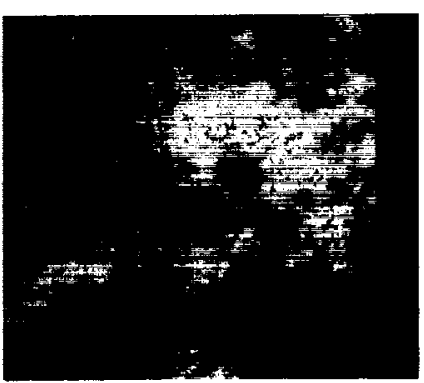

$2139 Z$

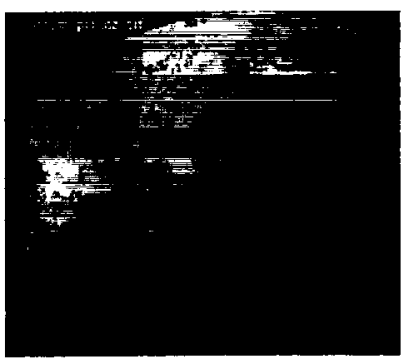

1249 Z

$1720 \mathrm{Z}$

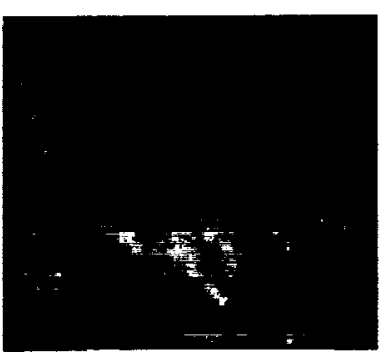

转

2034 Z
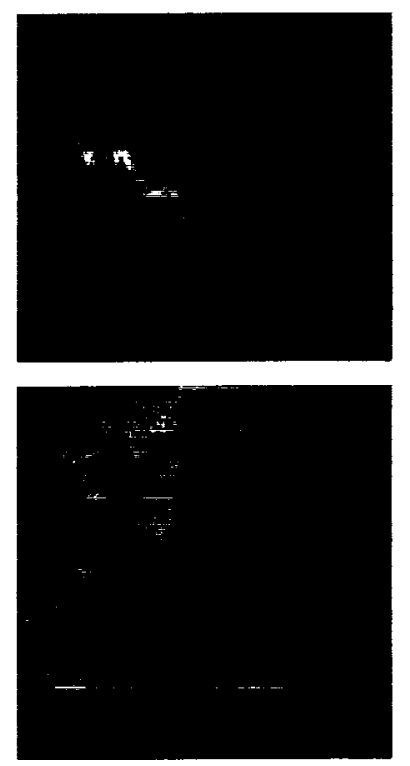

$1000 Z$

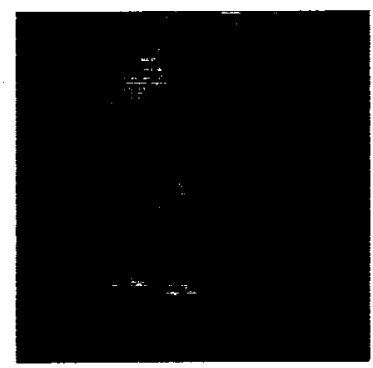

0739 Z 
Mean 1000-700 mb RH (\%)

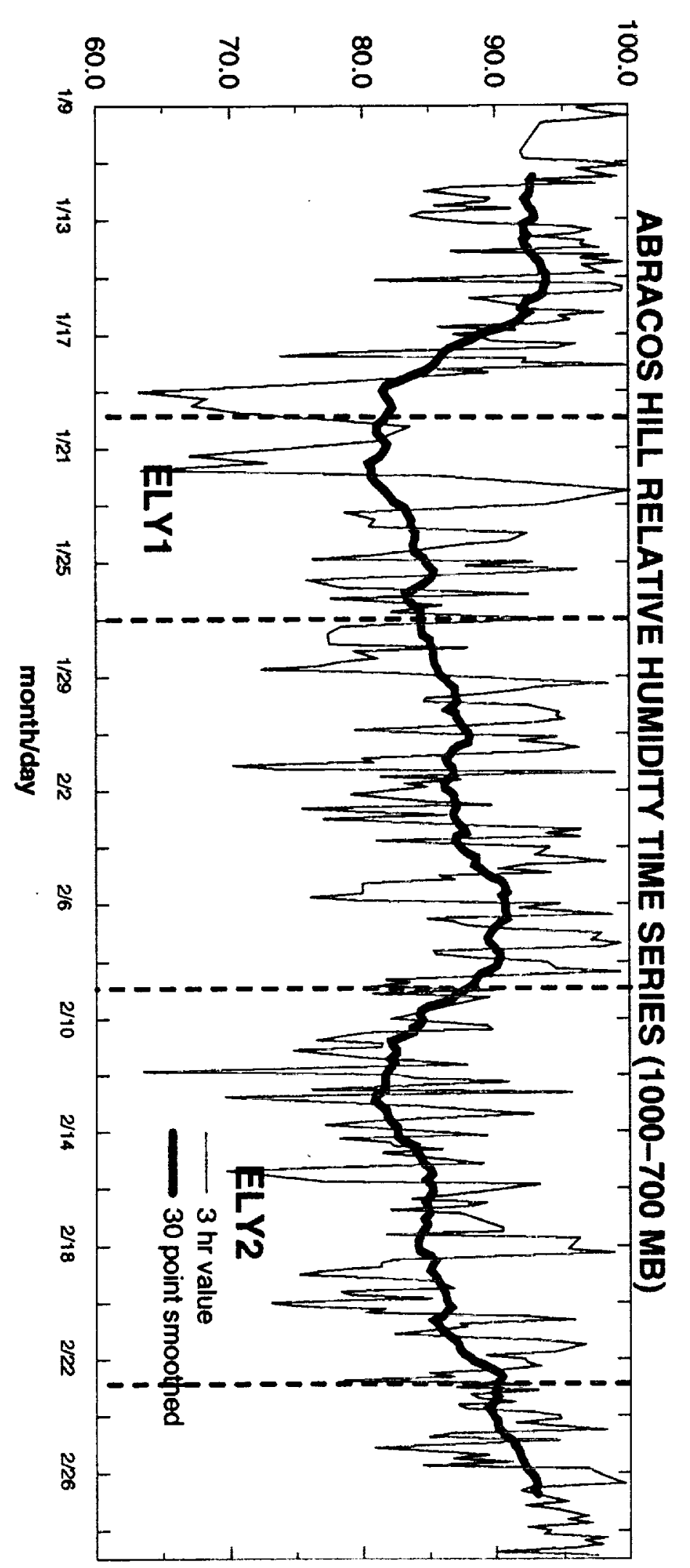

Conditional Rain Rate $(\mathrm{mm} / \mathrm{hr})$

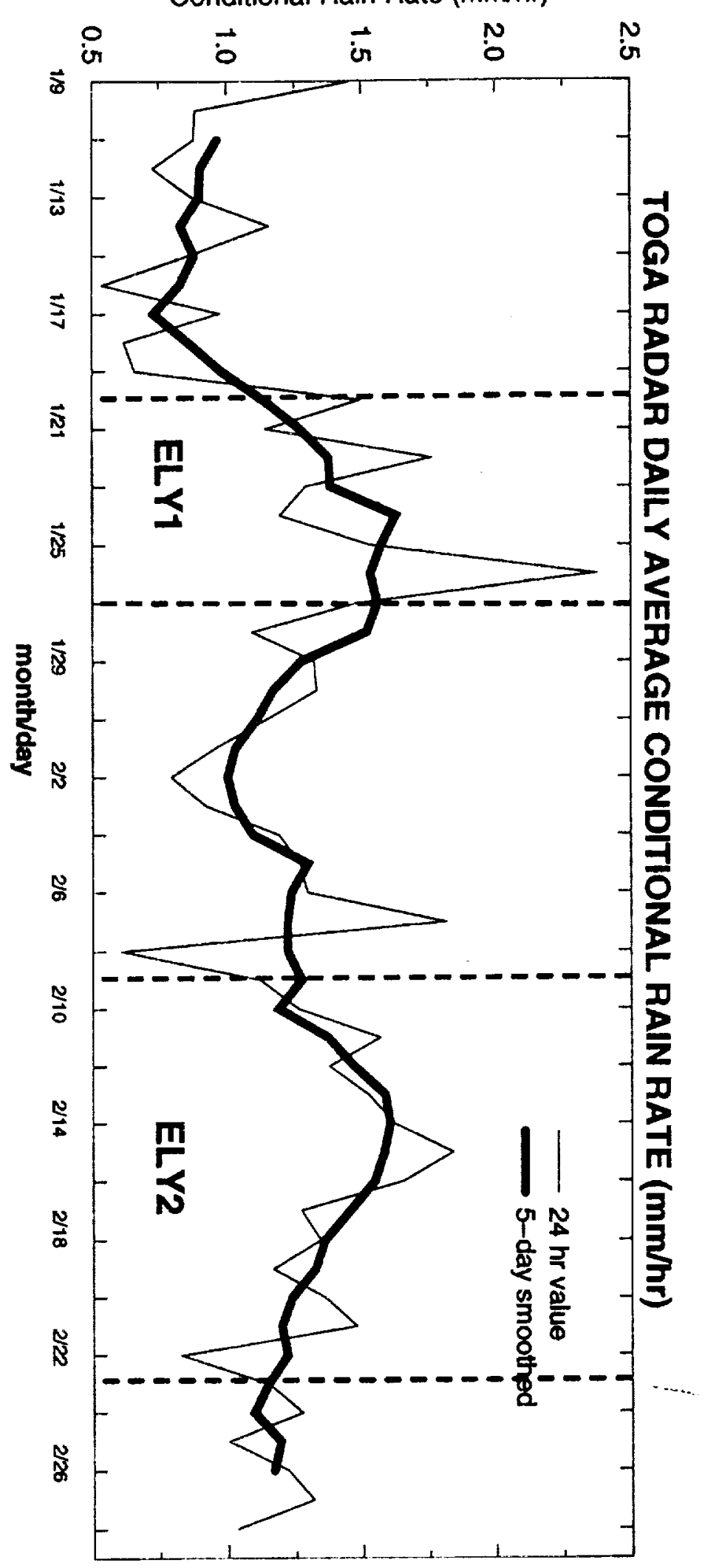




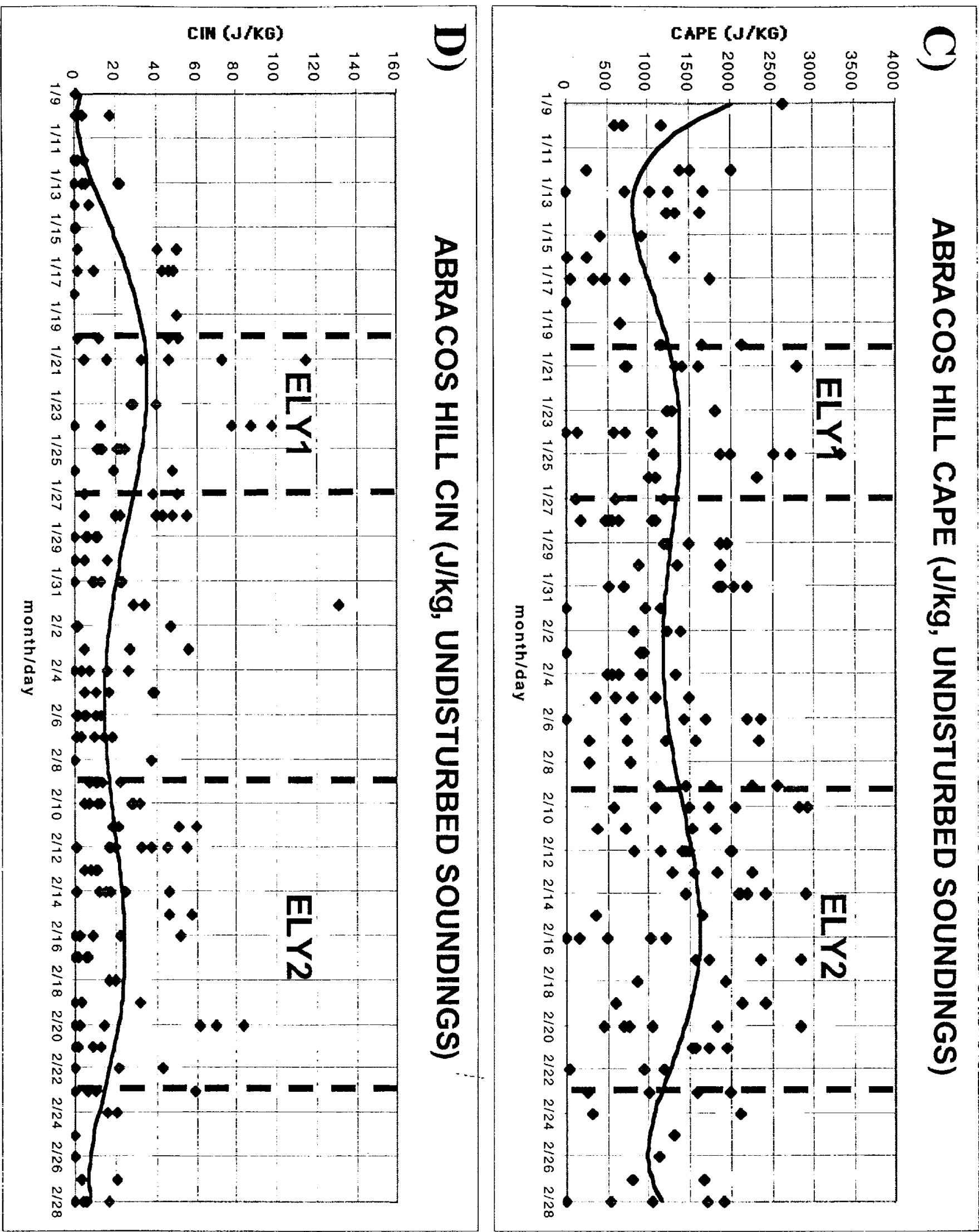

Fiçure 3 


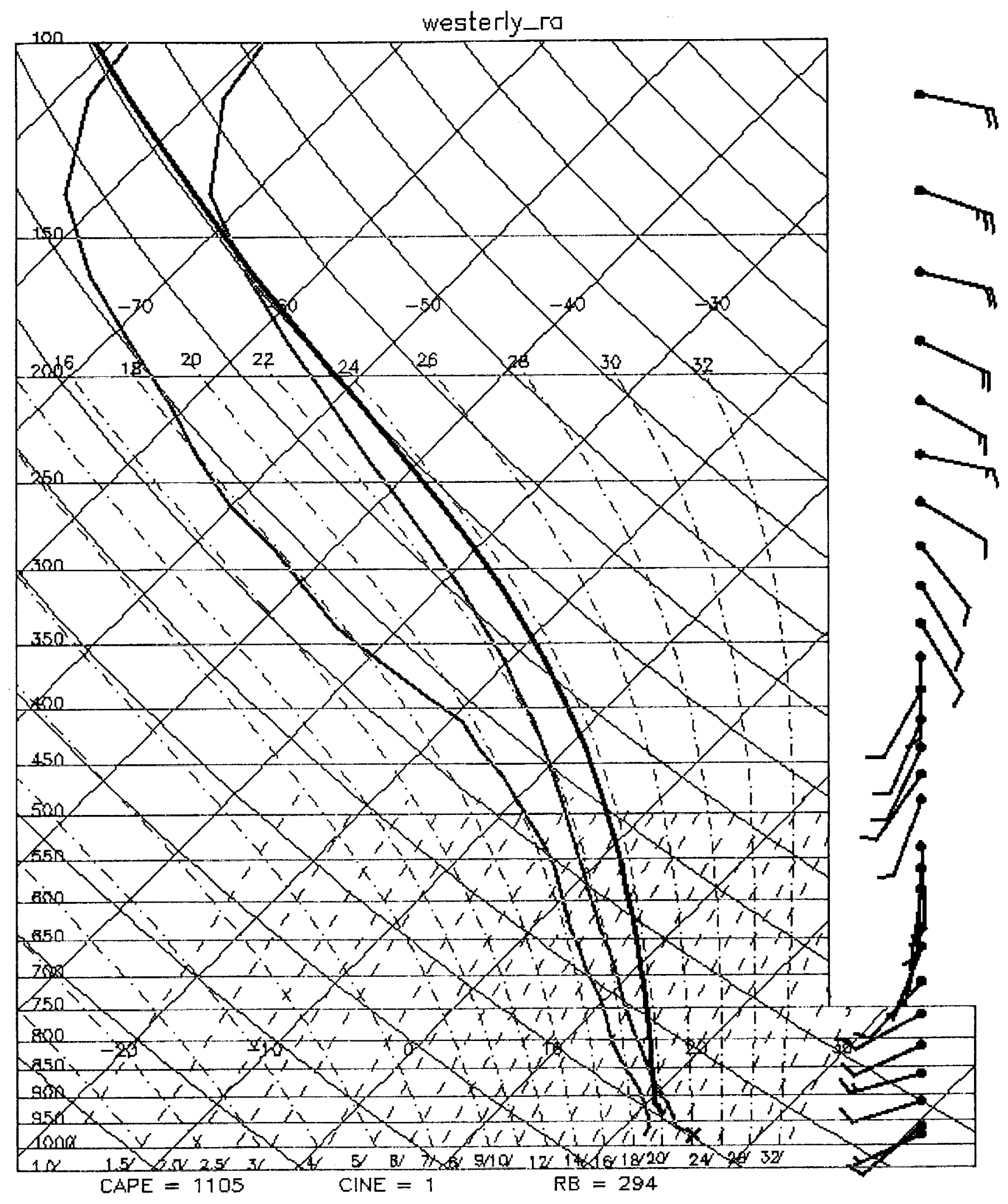




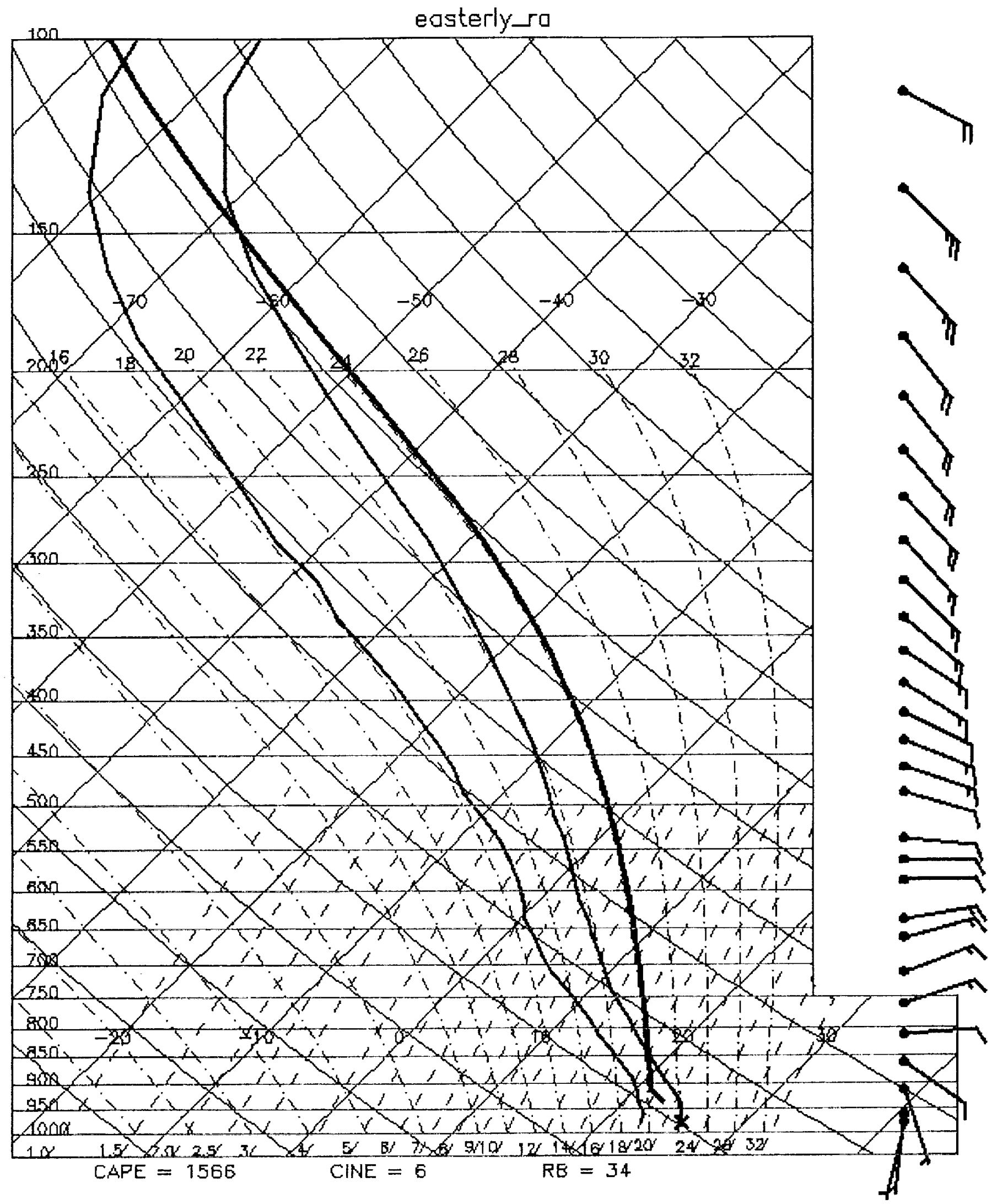


Figure 5

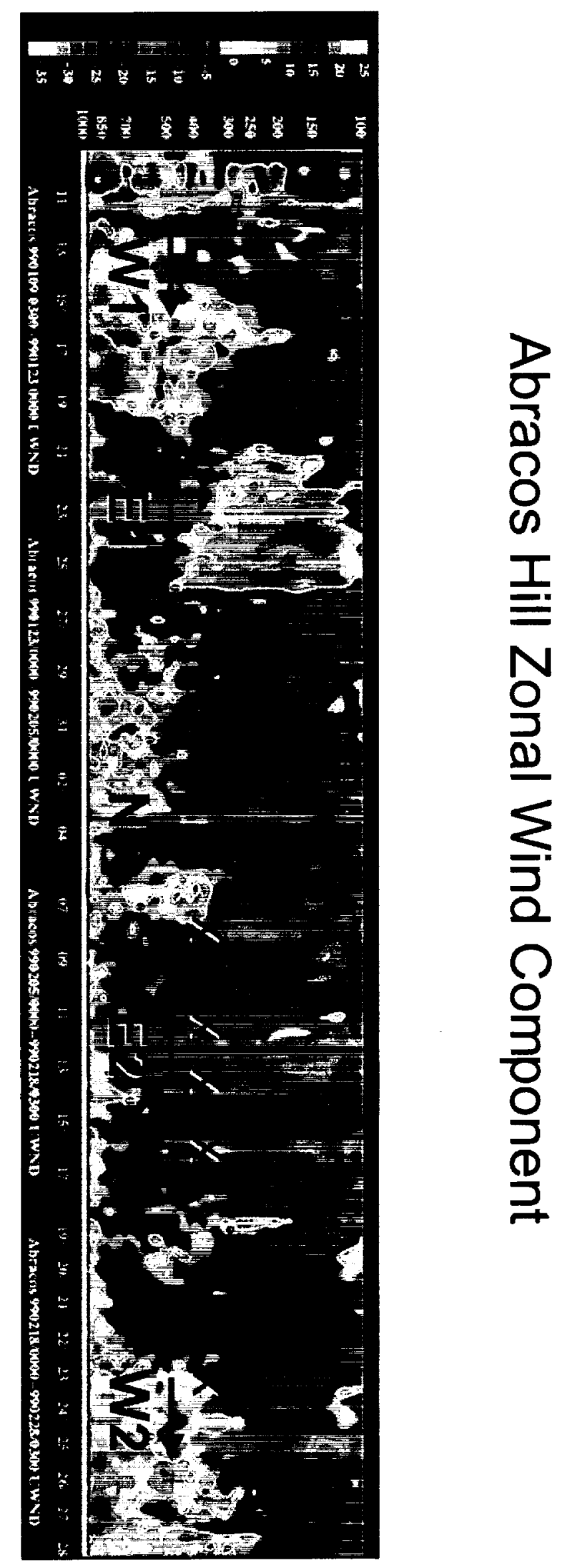


Figure 6

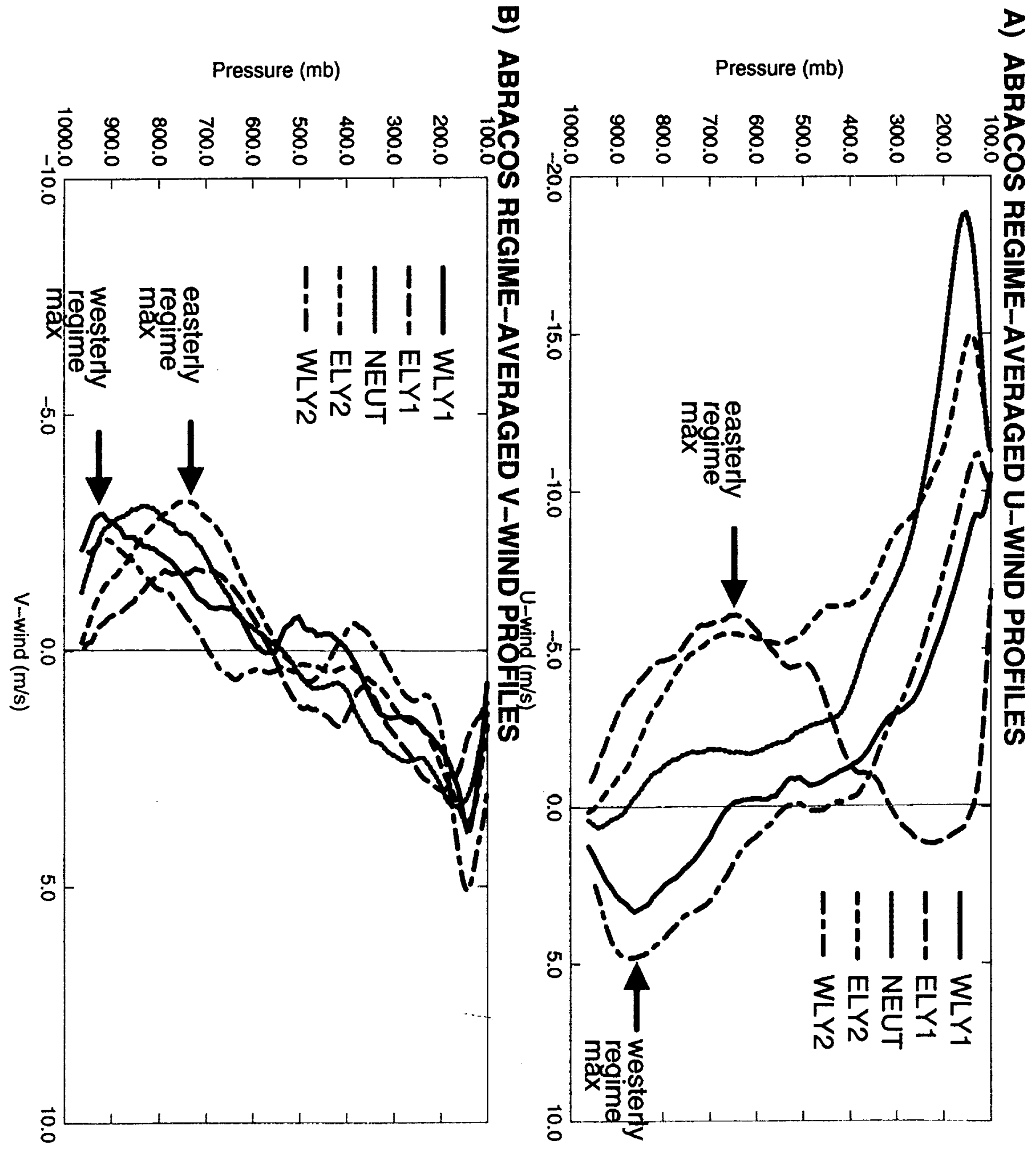




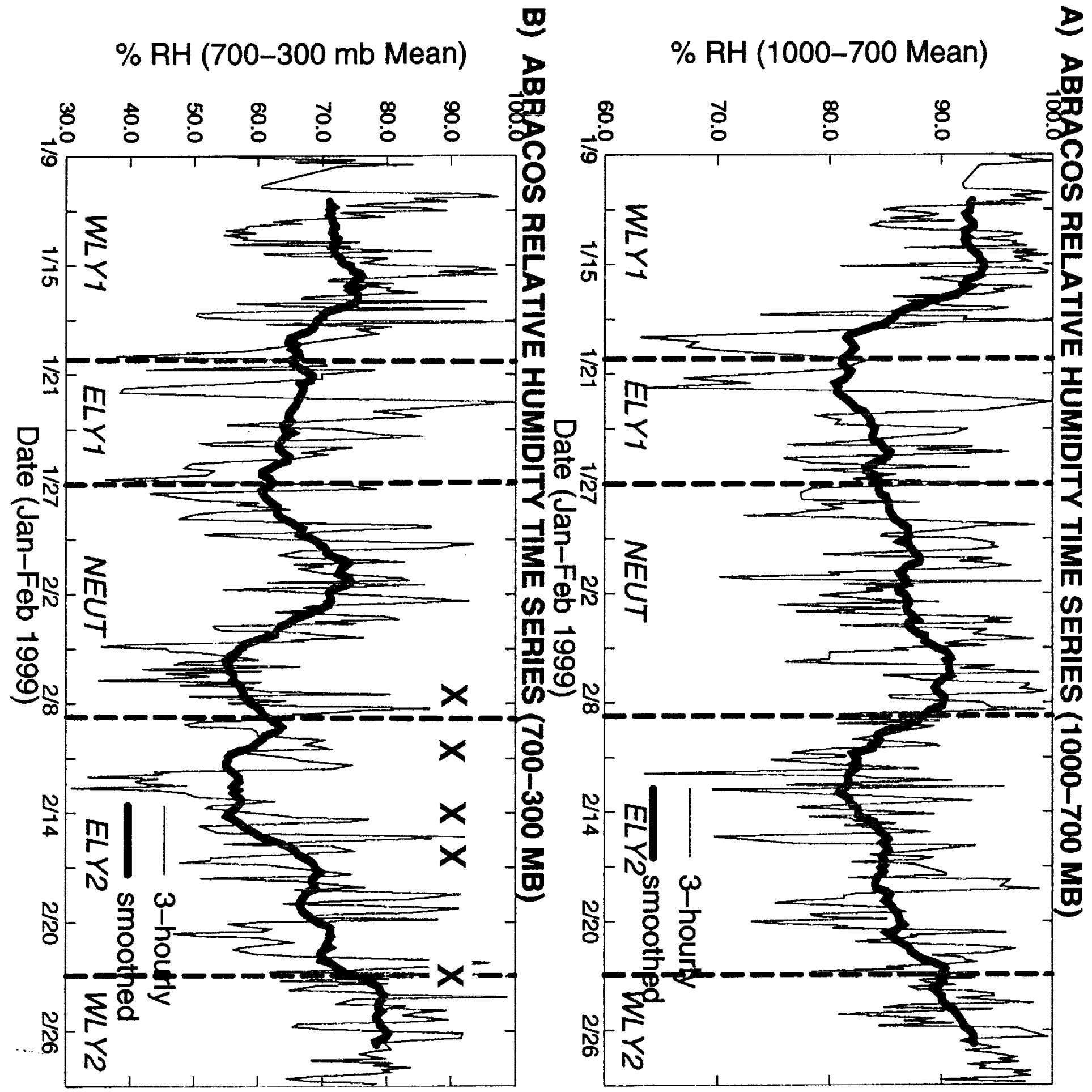




\section{Regime Airmass Origins 850 mb NASA DAO Trajectories}

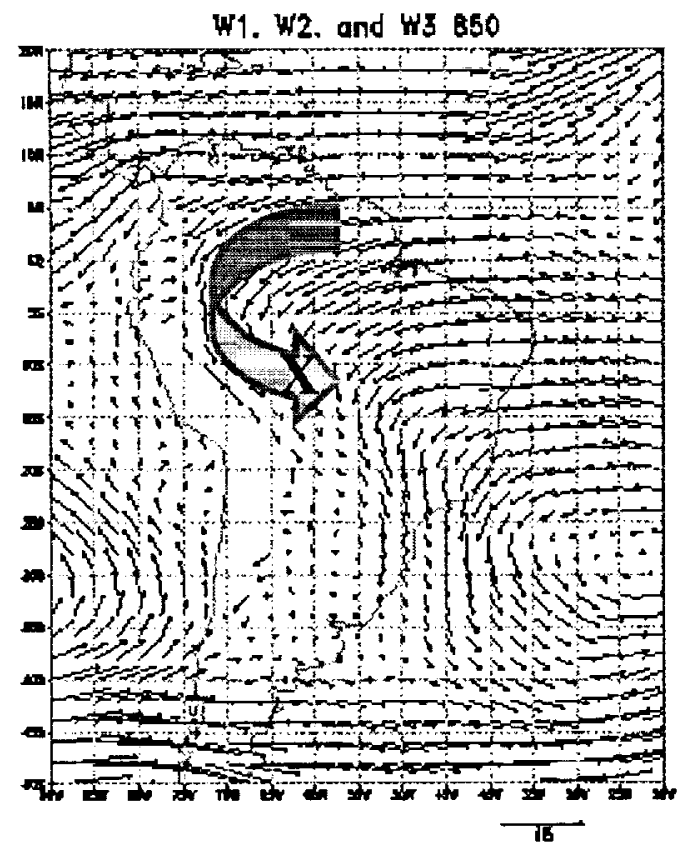

a) Westerly Regime

- Recurving flow

- Long fetch over moist forest
b) Easterly Regime

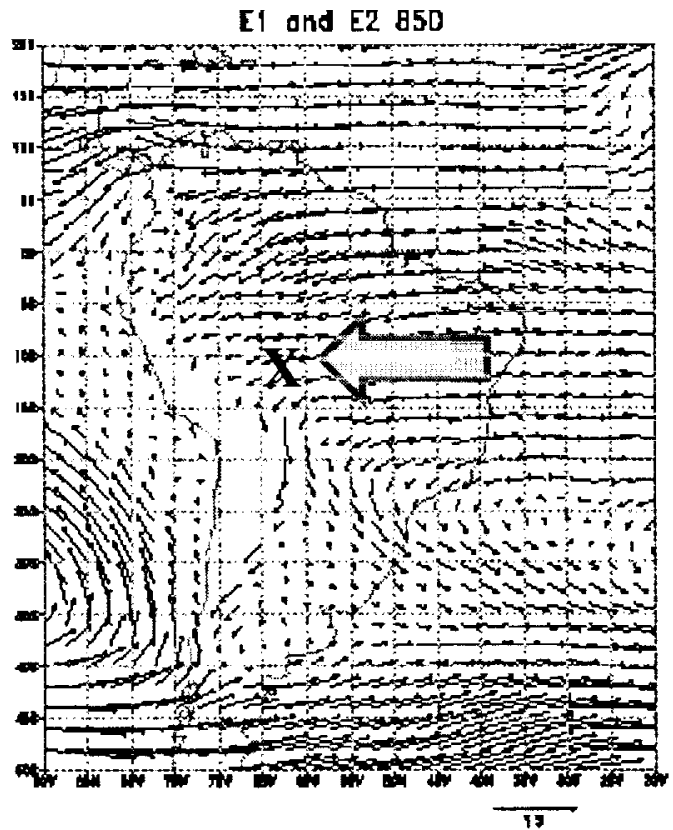

- Straight-in flow

- Fetch over semi-arid Brazilian Highlands 
22 Jan 1999

23 Jan 1999

24 Jan 1999

25 Jan 1999

26 Jan 1999 fall " 8 , wy 41 , ino:

is

$$
\text { in }
$$

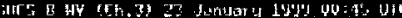

iv<smiles>[CH+]C[CH-]</smiles>
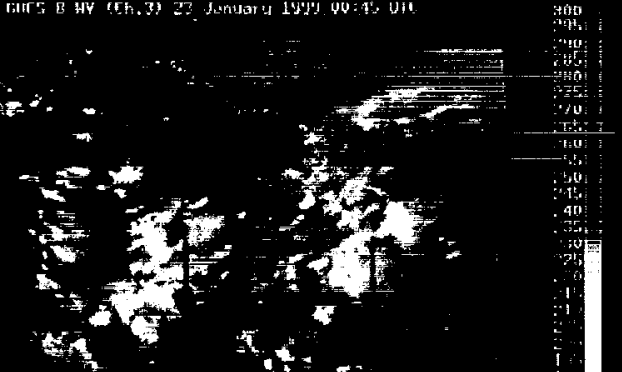

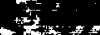

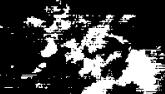

10

agn

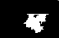

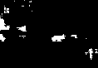

$+2 \cdot \frac{\pi}{7}$

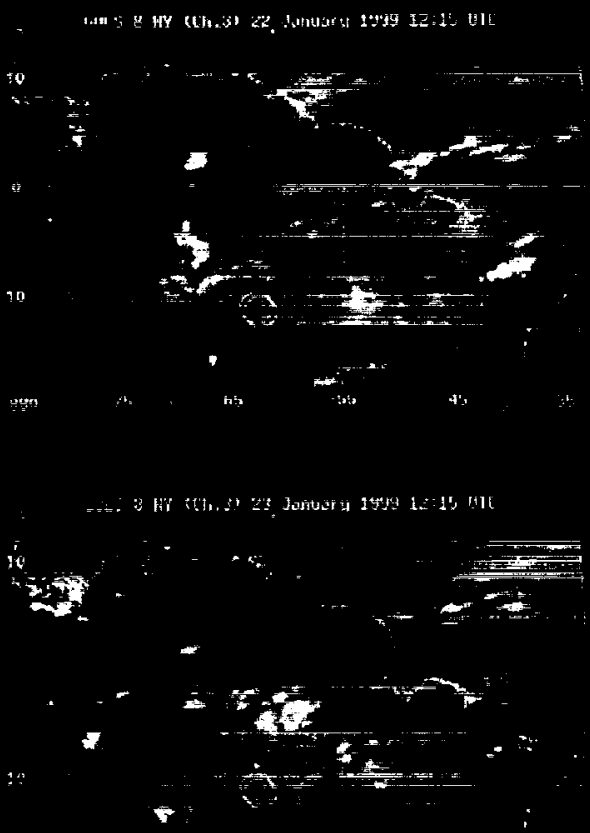

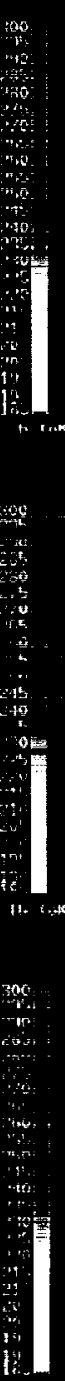

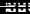
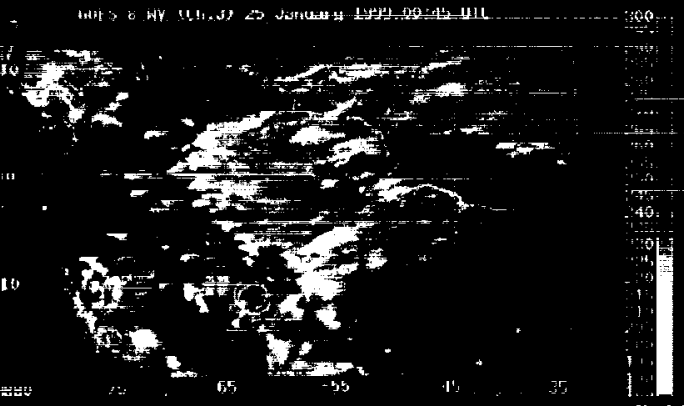

Lل1 :

waty

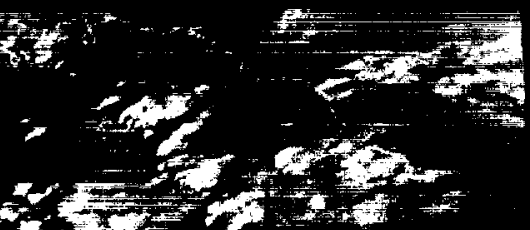

aty

$=4+24$
Ats

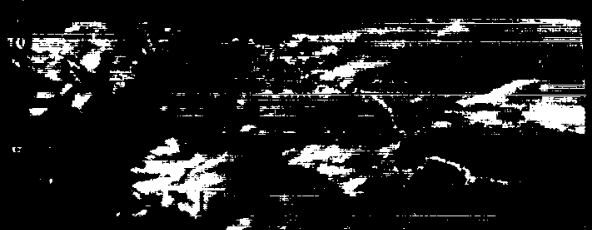

$\frac{4}{2}$

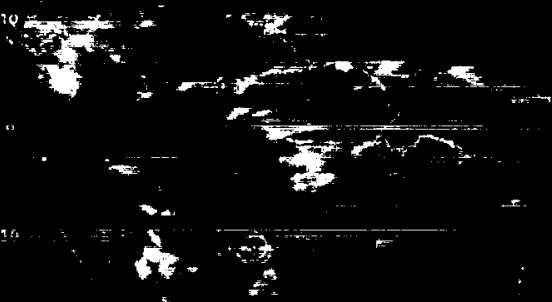

300

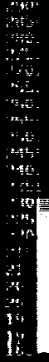

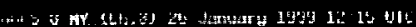

$\because$

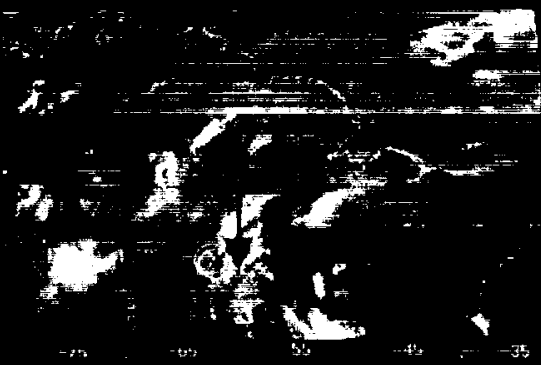


1 Feb 1999

2 Feb 1999

3 Fob 1999

4 Feb 1999

5 Feb 1999

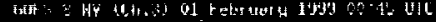

(a)

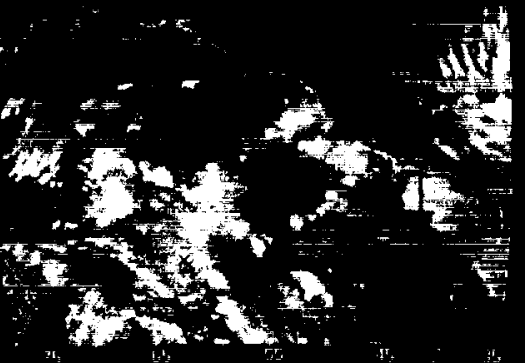

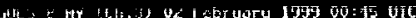

$\overline{3} \overline{0}$

is

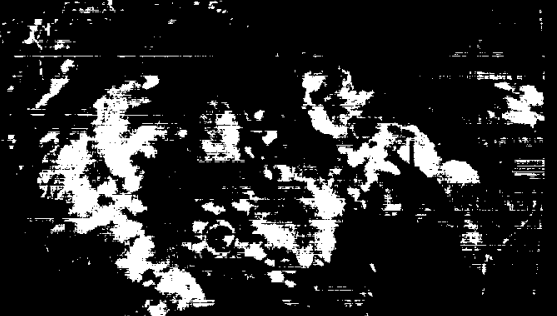

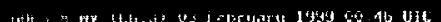

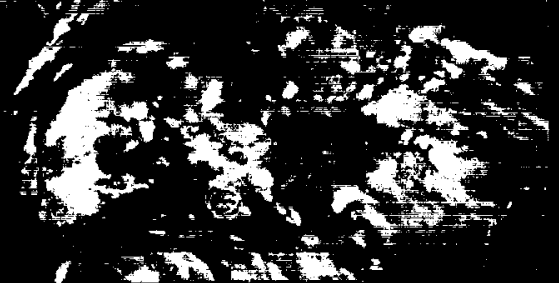

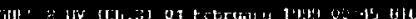

$=$

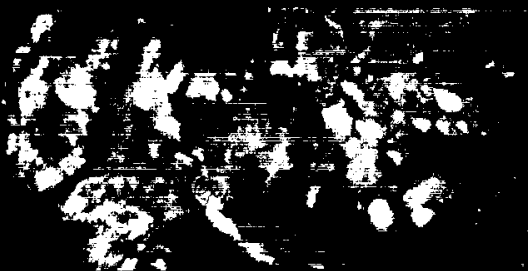

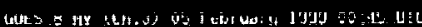

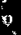
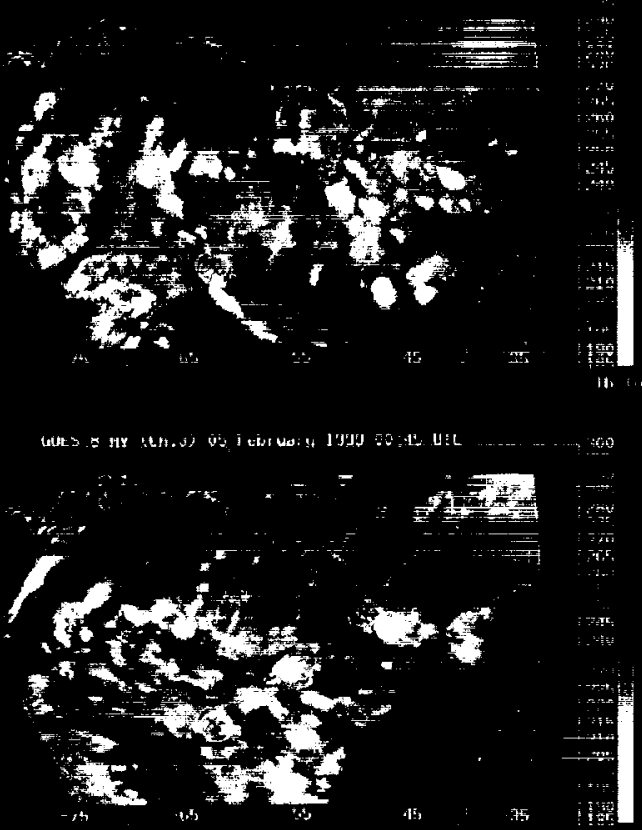

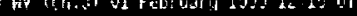

$=0$

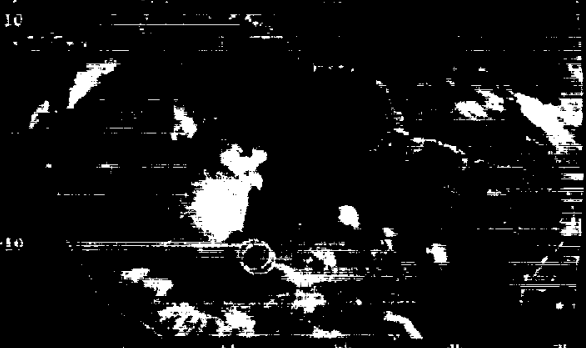

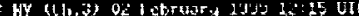

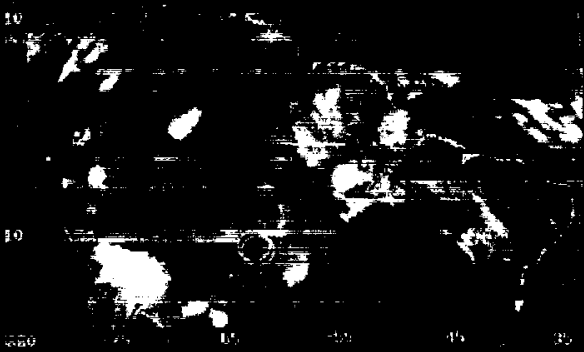

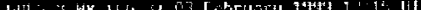

sis

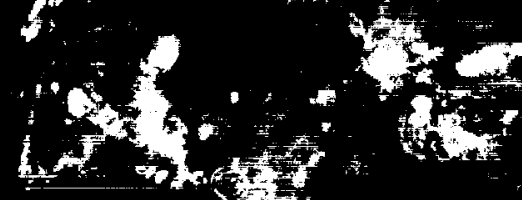

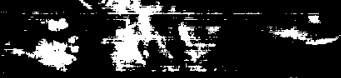

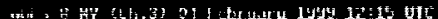

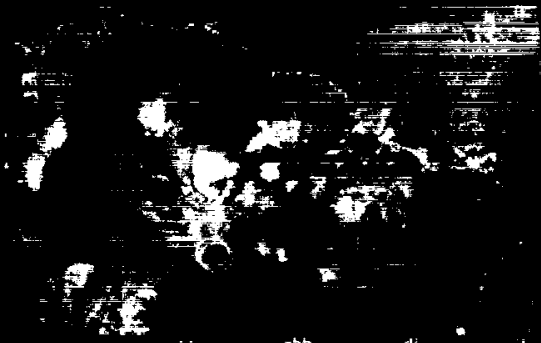

30

.

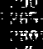

tis

?as a

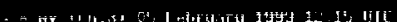

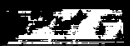

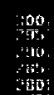

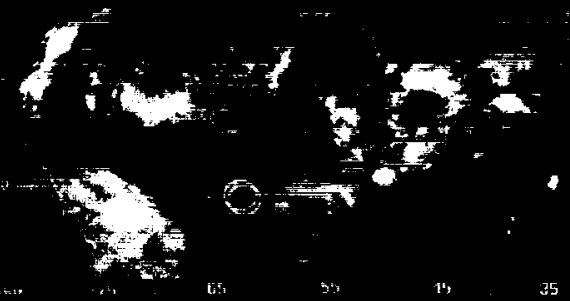

